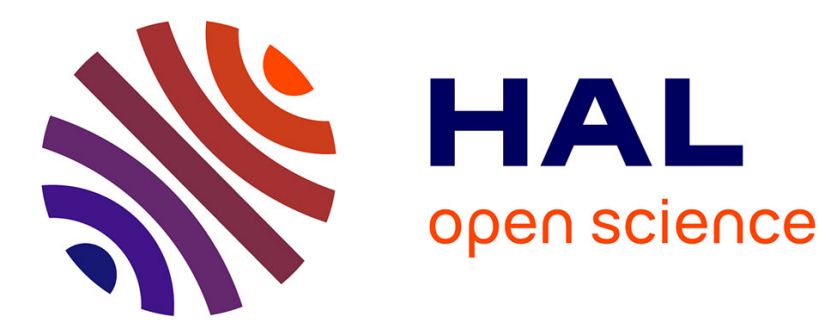

\title{
Ordered Hybrid Assembly of Palladium Nanoparticles and Perylene Molecules on an Alumina Template
}

Natalia Alyabyeva, Aimeric Ouvrard, Rémi Lazzari, Bernard Bourguignon

\section{To cite this version:}

Natalia Alyabyeva, Aimeric Ouvrard, Rémi Lazzari, Bernard Bourguignon. Ordered Hybrid Assembly of Palladium Nanoparticles and Perylene Molecules on an Alumina Template. Journal of Physical Chemistry C, 2019, 123 (31), pp.19175-19182. 10.1021/acs.jpcc.9b04147 . hal-02357080

\author{
HAL Id: hal-02357080 \\ https://hal.science/hal-02357080
}

Submitted on 17 Nov 2020

HAL is a multi-disciplinary open access archive for the deposit and dissemination of scientific research documents, whether they are published or not. The documents may come from teaching and research institutions in France or abroad, or from public or private research centers.
L'archive ouverte pluridisciplinaire HAL, est destinée au dépôt et à la diffusion de documents scientifiques de niveau recherche, publiés ou non, émanant des établissements d'enseignement et de recherche français ou étrangers, des laboratoires publics ou privés. 


\title{
Ordered Hybrid Assembly of Palladium Nanoparticles
}

\section{and Perylene Molecules on an Alumina Template}

\author{
Natalia Alyabyeva ${ }^{1 \S}$, Aimeric Ouvrard ${ }^{1 *}$, Rémi Lazzari $^{2}$ and Bernard Bourguignon ${ }^{1}$ \\ ${ }^{1}$ Institut des Sciences Moléculaires d'Orsay (ISMO), CNRS, Université Paris-Saclay, 91405 Orsay, France \\ ${ }^{2}$ Institut des NanoSciences de Paris (INSP), CNRS / Sorbonne Université, 75252 Paris, France
}

\begin{abstract}
Combining in a synergic way inorganic and organic matter at nanometre level has become a key research pathway for nanoelectronics, light harvesting, energy storage or sensing. Herein, we demonstrate the nanoscale ordering at room temperature of a two-dimensional hybrid assembly combining a long-range ordered array of Pd nanoparticles (NPs) with perylene molecules. The ordering, driven by the periodic superstructure of the $\mathrm{Al}_{2} \mathrm{O}_{3}$ ultrathin layer support, has been achieved for $0.9 \mathrm{~nm}$ diameter NPs and flat-lying molecules with a 2:1 perylene:NP relative ratio. At larger NP size and perylene coverage, molecules tilt up on alumina and adsorb on NPs. Combined near-field microscopy and optical spectroscopies provide a detailed understanding of the structural properties as a function of NP size and molecular coverage. This hybrid assembly opens the way to study at the molecular level the optical and electronic properties resulting from the coupling of organic molecules and nanoparticles using multi-scale surface sensitive techniques.
\end{abstract}

\section{- INTRODUCTION}


The main challenge on the material and nanoscience side, is to develop a versatile technology that could be used to build large scale, high density, high quality hybrid systems combining nanoelectrodes and molecules. So far, combining a metallic nanoparticle (NP), a quantum dot or a carbon nanotube with a single molecule as an elementary unit is one of the challenges in future nanoelectronics devices. ${ }^{1-4}$ Different hybrid systems have already been studied where a molecule interconnects nanoelectrodes of a break junction ${ }^{5-8}$ or bridges NP dimers in solution. ${ }^{9-10} \mathrm{~A}$ molecule or a single atom can also be placed in the tunnel junction of a scanning probe microscope on a surface. ${ }^{11-12}$ These configurations allow to study the conductance through hybrid systems, but can hardly provide information concerning the electronic state and the bonding of the molecules. By contrast, a bottom-up approach to grow nanoparticles ordered at nanometer scale over micrometer distances, that nanolithography cannot yet achieve, is a promising start to learn about molecule - NP ordering and coupling. Metallic NPs with plasmonic or magnetic properties are known to grow along a regular array of nucleation points at the surface of $\mathrm{Al}_{2} \mathrm{O}_{3}$ ultrathin layer on $\mathrm{Ni}_{3} \mathrm{Al}(111),{ }^{13-15}$ of $\mathrm{TiO}_{x}$ reconstruction on $\mathrm{Pt}(111)^{16}$, of strained $\mathrm{MgO} / \mathrm{Mo}(100)$ films ${ }^{17}$ and of graphene/Ir(111). ${ }^{18}$ The latter system has demonstrated a surprisingly long-range ordering with an almost perfect Poisson distribution of the NP size, but their strong electronic coupling with the substrate, as well as NP mobility upon molecular adsorption ${ }^{19}$ prevents its potential use in molecular electronics. In the case of NPs/MgO/Mo and NPs/TiO variety of ordered phases can be produced, the quality of ordering is less controlled than on alumina or on graphene. The commensurate relationship of the $\mathrm{Al}_{2} \mathrm{O}_{3}$ bi-layer on $\mathrm{Ni}_{3} \mathrm{Al}(111)$ leads to the presence of two lattice superstructures, called "network" and "dot" according to microscopy, with periodicities of $2.38 \mathrm{~nm}$ and $4.12 \mathrm{~nm}$ that can serve as a template to the ordered 
nucleation of various types of bimetallic NPs. ${ }^{14,15}$ This system, which has shown a strong potential to produce model nanoparticles for heterogeneous catalysis ${ }^{20,21}$ and data storage ${ }^{22}$ purposes, has been selected for the present study. The presence of the thin oxide layer limits charge transfer from the substrate with respect to metallic templates ${ }^{23,24}$ and favors intermolecular and molecule-NP interactions, while remaining compatible with surface science techniques that require a conductive surface.

The selected molecule, namely perylene $\left(\mathrm{C}_{20} \mathrm{H}_{12}\right)$ consisting of five planar aromatic benzene rings, is interesting in electronic applications as photoconductor ${ }^{25}$ or in OLEDs as dopant. ${ }^{26}$ This has led to several studies of the growth mechanisms and of molecule-surface and intermolecular interactions of perylene-based molecules. They form well-ordered single and multilayers on various noble metallic surfaces. It was shown by scanning tunneling microscopy (STM) that $\pi$ orbitals normal to the carbon backbone favor anchoring and 2-D ordering of flat-lying molecules on metallic single crystal surfaces. ${ }^{27-30}$ Reversible transitions from a "2-D gas" to a liquid phase and subsequently to a crystalline phase have been observed during the growth on $\mathrm{Ag}(110)$ as coverage increases using grazing incidence fast atom diffraction. ${ }^{31} \mathrm{On} \mathrm{Ag}(111)$, perylene binds strongly to adsorption sites and intermolecular interactions play a small role. ${ }^{32}$ In the multilayer regime, perylene molecules remain parallel to the substrate due to the strong surface anchoring and $\pi$-stacking that stabilizes the multilayer. ${ }^{33}$ Probing in-plane stretching vibration of $\mathrm{C}-\mathrm{H}$ bonds located along the perylene perimeter is a way to get some insights on molecular orientation and intermolecular and surface coupling. ${ }^{28,32-35}$ There are far fewer studies on interaction of molecules with oxides. Recently, Cu phthalocyanine ${ }^{36}$ and perylene ${ }^{37}$ on alumina thin film on $\mathrm{Ni}_{3} \mathrm{Al}(111)$ have been investigated by STM and near-edge X-ray absorption fine structure (NEXAFS) spectroscopy, 
respectively. For Cu phthalocyanine, a weak ordering on the alumina template has been observed

at low coverage, while at higher coverage 3-D islands are formed. ${ }^{36}$ For perylene $/ \mathrm{Al}_{2} \mathrm{O}_{3}$, single and multilayers have been achieved with different molecular orientations, ranging from almost flatlying $\left(10^{\circ}\right)$ to up-standing molecules $\left(73^{\circ}\right)$ depending on the growth temperature, the molecular flux and the deposited amount. ${ }^{37}$

In this work, we describe the long-range ordering of perylene molecules inserted into an ordered array of palladium nanoparticles grown on ultra-thin alumina template on $\mathrm{Ni}_{3} \mathrm{Al}(111)$. It is compared to adsorption on the bare alumina film. Systematic investigations have been conducted using microscopy, optical and vibrational spectroscopies. Ordered adsorption phases have been evidenced. The effects of coverage and NP size on the layer ordering and electronic density of states and optical properties have been scrutinized to rationalize the respective roles of molecule/alumina and molecule/NP interactions.

\section{- EXPERIMENTAL METHODS}

Sample growth and characterization were performed in $\mathrm{a}<2 \times 10^{-10} \mathrm{mbar}$ base pressure ultrahigh vacuum (UHV) chamber. The polished $\mathrm{Ni}_{3} \mathrm{Al}(111)$ single crystal (Surface Preparation

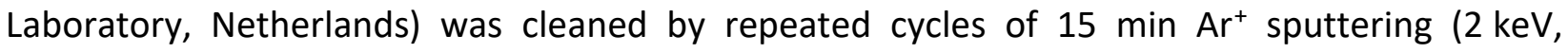
$15 \mu \mathrm{A} / \mathrm{cm}^{2}$ ) and vacuum annealing at $1123 \mathrm{~K}$ for $15 \mathrm{~min} . \mathrm{Al}_{2} \mathrm{O}_{3}$ ultra-thin oxide film was grown using an optimized procedure to achieve long-range ordered NPs. ${ }^{38}$ It consists in surface oxidation in $5 \times 10^{-8} \mathrm{mbar}_{2}$ atmosphere ( 90 Langmuir dose; 1 Langmuir $=1.33 \times 10^{-6} \mathrm{mbar} . \mathrm{s}$ ) at $1143 \mathrm{~K}$, $\sim 140 \mathrm{~K}$ above the standard recipe reported in the literature, ${ }^{13,14,39,40}$ followed by annealing at 
$1193 \mathrm{~K}$. NPs were grown on $\mathrm{Al}_{2} \mathrm{O}_{3}$ at $300 \mathrm{~K}$ by Pd vapor deposition (99.98\% purity) at a rate of 0.1$0.2 \AA /$ min. Equivalent thicknesses of 0.05 and 0.2 monolayers $(M L)$ of Pd were deposited $(1 \mathrm{ML}=$ $5.1 \times 10^{14}$ atoms.cm ${ }^{-2}$ ). Pd flux calibration was performed by a quartz microbalance and crosschecked by STM on specific terraces where a layer by layer growth occurs. ${ }^{38}$ Perylene was evaporated from its powder phase heated at $400 \mathrm{~K}$ either before or after NP deposition. Perylene flux direction was oriented at $45^{\circ}$ from the sample normal, allowing to perform optical spectroscopy during the growth. The estimated flux of incoming molecules on alumina was around $\sim 6 \pm 1 \times 10^{12} \mathrm{~min}^{-1} \cdot \mathrm{cm}^{-2}$, according to a calibration done by STM. Two deposits corresponding to $\sim 0.4$ and $\sim 1.2$ equivalent $\mathrm{ML}$ of perylene were performed (see the STM result section for definition). Molecule growth was also followed by differential reflectance spectroscopy (DRS); experimental set-up and principle are described elsewhere. ${ }^{41} \mathrm{~A}$ deuterium/halogen lamp was used, giving access to UV/Vis/NIR spectral range from 1.1 to $5 \mathrm{eV}$, but window absorption limited the UV range below $3.5 \mathrm{eV}$. The reflected signal from the sample and a reference spectrum used to correct from lamp drift were recorded in parallel by two identical low-noise spectrometers (Maya, Ocean Optics). The reflected intensity $R$ during the growth was normalized by that of the same surface prior to deposition to determine the $\Delta R / R$ signal. Light was unpolarized. But since the incident/collection angles relative to sample normal were close to $10^{\circ}$, the exciting electric field was mainly aligned parallel to the surface thus reducing the DRS sensitivity to out-of-plane dielectric behavior. A signal to noise ratio better than $10^{3}$ could be easily achieved after the correction from lamp drift and dark signal, for a $10 \mathrm{sec}$ acquisition time (200 averaged spectra of 50 ms duration). Perylene organization on $\mathrm{Al}_{2} \mathrm{O}_{3}$ film without and with NPs were also studied with a STM microscope operating in UHV at room 
temperature (ScientaOmicron). Electronic structure of the molecule and the impact of its adsorption on NPs were probed by STM spectroscopy (STS) on individual perylene molecules and Pd NPs. STS spectra were correlated with DRS reflectivity dependence on coverage. Tungsten tips were prepared by electrochemical etching in $\mathrm{KOH}$ with subsequent thinning by dual-focused ion beam (FEI) to produce $7 \mathrm{~nm}$ tip radius (beam parameters: $1.5 \mathrm{nA}, 30 \mathrm{keV}$ ). ${ }^{42}$ STM images were processed using WSxM software. ${ }^{43}$ It should be mentioned that imaging was challenging at room temperature since regulation parameters for molecules and NPs are very different. Indeed, to image perylene with a high contrast, the STM tunnel current must be greatly increased (>500 pA) compared to the case of NPs (10-20 pA typically). Sum frequency generation (SFG) measurements were performed at room temperature using two $p$-polarized collinear laser beams: a nearinfrared pulse (12407 $\mathrm{cm}^{-1}$ wavenumber, $7 \mathrm{~cm}^{-1}$ width, $3 \mathrm{ps}$ duration) and an infrared pulse (3050 $\mathrm{cm}^{-1}$ wavenumber, $150 \mathrm{~cm}^{-1}$ width, $140 \mathrm{fs}$ duration) which covers the spectral region of aromatic $\mathrm{C}-\mathrm{H}$ stretch vibrations of perylene. The intensity and frequency of the $\mathrm{C}-\mathrm{H}$ band give access to valuable information on the molecular orientation, intermolecular and molecule/NP coupling. Details of SFG spectrum fitting and band deconvolution are given elsewhere. ${ }^{44,45}$ STM and SFG measurements were performed at a given coverage while DRS was recorded in real-time during the growth.

\section{- EXPERIMENTAL RESULTS}

STM characterizations. Figure 1 compares at the same scale $\left(15 \times 8 \mathrm{~nm}^{2}\right)$, STM topography of the bare alumina thin film and after deposition of 0.4 and $1.2 \mathrm{ML}$ of perylene. Fourier analysis, 
supporting long-range order and perylene adsorption phases are given for each STM images. Topography profiles along dotted white lines are provided in supplementary information (Figure SI-1). As demonstrated in Refs. 13-15, the periodic superstructure of the alumina thin film is evidenced by STM (Figure 1a) by resonant elastic tunneling through in-gap states at $3.2 \mathrm{~V}$, while at $0.7 \mathrm{~V}$ (Figure $1 \mathrm{~b}$ ) STM rather probes the surface topography at atomic resolution with a lower corrugation. The network superstructure of $(\sqrt{67} / \sqrt{3} \times \sqrt{67} / \sqrt{3}) \mathrm{R} 18^{\circ}$ unit cell (phase $\left.\mathrm{P}_{0}\right)$ and $2.38 \mathrm{~nm}$ periodicity is highlighted by a white rhomb. ${ }^{39}$ Three different ordered adsorption phases of perylene that we call $P_{1}, P_{2}$ and $P_{3}$ are evidenced, depending on the amount of molecules. After 0.4 ML deposition, a hexagonal periodic phase of perylene binding along the network structure is observed (Figure $1 c)$. This structure $\left(P_{1}\right)$ has a $(1 \times 1)$ unit cell relative to $P_{0}$. The size of perylene molecules is $1 \mathrm{~nm}$ and their apparent height is $1 \AA$ (Figure SI-1b), suggesting that molecules are flat-lying, in agreement with perylene conformation and by assuming that STM mainly images the topography changes with a minor contribution of the change of the electronic density states between bare alumina and perylene on alumina. For the same amount, another phase with a density three times greater, still in registry with the alumina periodic structure, can be also observed on separated terraces (Figure 1d). In this case, perylene is organized along a $(1 / \sqrt{3} \times 1 / \sqrt{3}) \mathrm{R} 30^{\circ}$ phase $\left(\mathrm{P}_{2}\right)$ relative to $\mathrm{P}_{0}$ with one perylene per unit cell. The $24^{\circ}$ rotation of $P_{2}$ relative to $P_{1}$ is due to the presence of two alumina orientation domains rotated by $24^{\circ}$ relative to each other on $\mathrm{Ni}_{3} \mathrm{Al}(111) .{ }^{46,47,38}$ In $\mathrm{P}_{2}$, each protrusion corresponds to an individual perylene molecule having a $1 \mathrm{~nm}$ size, $1.1 \AA ̊$ apparent height and separated from each other by $2.38 / \sqrt{3}=1.37 \mathrm{~nm}$ (Figure SI-1b). With the help of Figure $1 \mathrm{c}$ and $1 \mathrm{~d}$, the flux of perylene can be

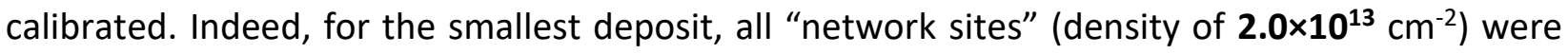


occupied by perylene as well as few terraces $(<10 \%$ of sample coverage) with a three times larger perylene coverage $\left(5.9 \times 10^{13} \mathrm{~cm}^{-2}\right)$, leading to a molecular flux of about $6 \pm 1 \times 10^{12} \mathrm{~min}^{-1} \cdot \mathrm{cm}^{-2}$. If the saturation coverage $(1 \mathrm{ML})$ is defined as 1 perylene per network point, then 4 (12) min of deposit corresponds to 1.2 (3.6) ML; we prefer hereafter to define the ML relative to the denser structure of the substrate like on $\mathrm{Ag}(110)$, leading to the two deposits of 0.4 and $1.2 \mathrm{ML}$, quoted above.

(a)

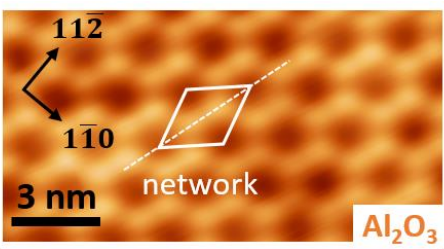

(c)

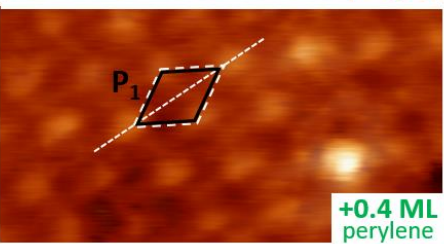

(e)

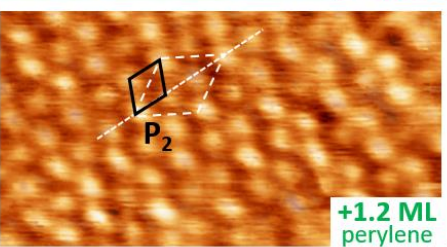

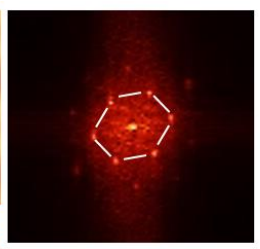
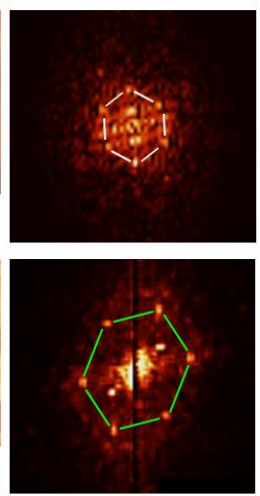

(b)

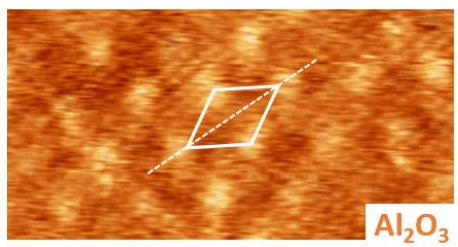

(d)

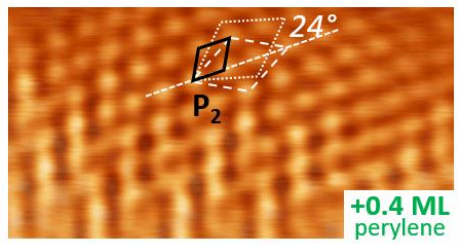

(f)

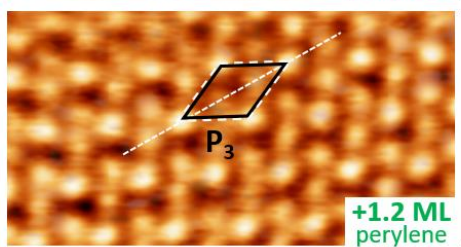

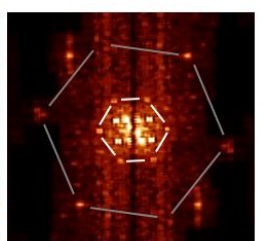
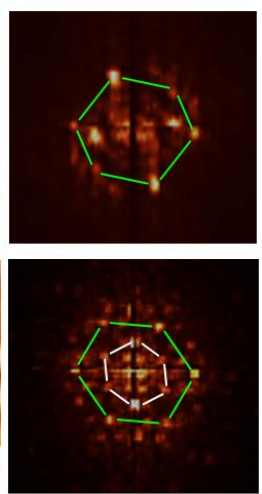

Figure 1. STM images [15×8 $\mathrm{nm}^{2}, 3.2 \mathrm{~V}$ and $50 \mathrm{pA}$ in (a), $0.7 \mathrm{~V}$ and $12 \mathrm{pA}$ in (b-f)] of clean alumina film $(a, b)$ and for two different perylene deposits: (c, d) 0.4 and (e, f) $1.2 \mathrm{ML}$. The unit cell of the $\mathrm{Al}_{2} \mathrm{O}_{3}$ "network" superstructure $(\sqrt{6} 67 / \sqrt{3} \times \sqrt{67} / \sqrt{3}) \mathrm{R} 18^{\circ}$, is evidenced by white rhombs. Adsorption phases of perylene are represented by black rhombs $\left(P_{1}:(1 \times 1), P_{2}:(1 / \sqrt{3} \times 1 / \sqrt{3}) R 30^{\circ}\right.$ and $P_{3}:(1 \times 1)$ relative to the network phase $\left.\mathrm{P}_{0}\right)$. A 50/50\% superposition of the raw image with its Fourier filtered image was done for $e$ and $f$ to enhance perylene structure contrast. Profiles along dashed lines are shown in Figure SI-1 of suppl. information. For each STM image is given the Fourier analysis where white lines indicate the network superstructure; grey lines the atomic periodicity and green lines the different perylene adsorption phases.

At higher coverage (1.2 ML), two phases of perylene can co-exist on the surface: (i) one phase is very close to $P_{2}$ but with a slight preferential orientation of molecules along the $[1 \overline{1} 0]$ direction of the substrate where molecules located on network sites appear brighter, (Figure 1e) and (ii) 
another phase $\mathrm{P}_{3}$ having the same density as $\mathrm{P}_{2}$ but with a stronger corrugation at network sites (Figure 1f). Both phases $P_{2}$ and $P_{3}$ are in registry with the network superstructure. $P_{3}$ has $(1 \times 1)$ unit cell relative to $P_{0}$ with 3 molecules per unit cell. The size of ordered domains of $P_{2}$ or $P_{3}$ is around 10-20 nm with an apparent layer thickness ranging from 1 to $2.5 \AA$ (Figure SI-1b).

(a)
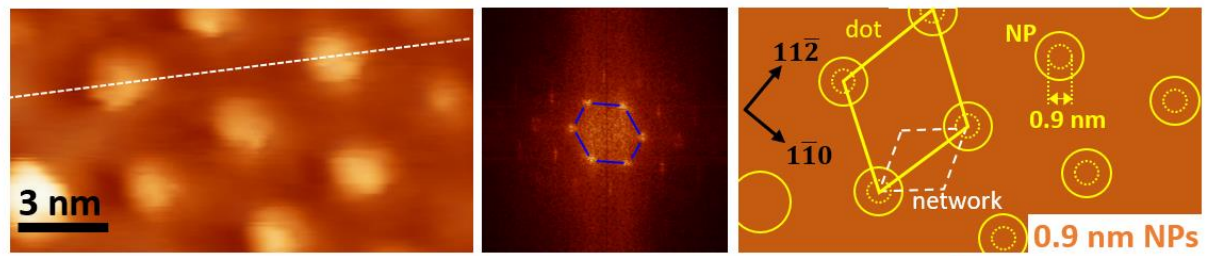

(b)
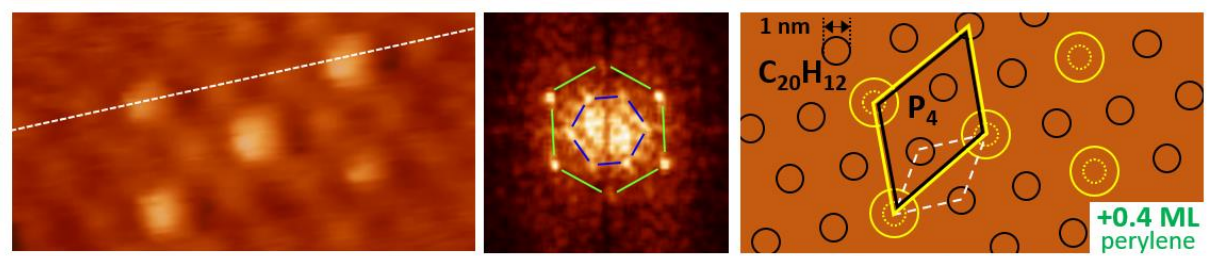

(c)
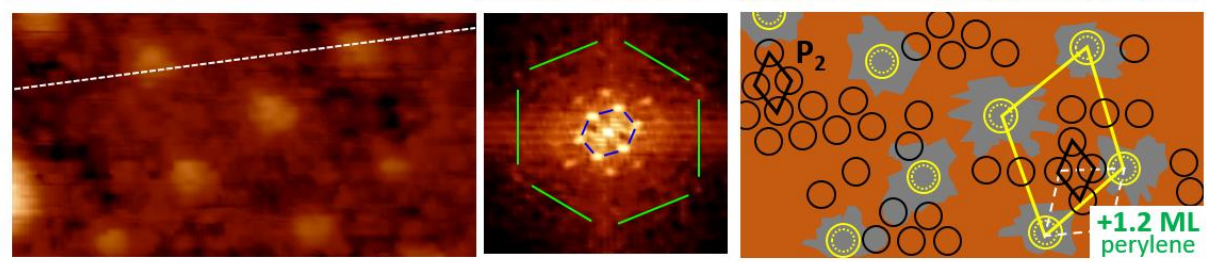

Figure 2. Left: STM images [ $\left.15 \times 8 \mathrm{~nm}^{2}, 0.7 \mathrm{~V}, 12 \mathrm{pA}\right]$ of $0.9 \mathrm{~nm}$ large Pd NPs (0.05 ML) supported on alumina film before (a) and after deposition of (b) 0.4 and (c) $1.2 \mathrm{ML}$ of perylene. Right: schematic representations of NP array in yellow and perylene molecules in black along two phases $\mathrm{P}_{4}$ and $\mathrm{P}_{2}$ (black rhomb). In (c), only ordered molecules are highlighted. Dotted circles shows real NPs size without tip-surface convolution. ${ }^{21}$ Grey areas stands for perylene adsorbed around NPs. Profiles along dashed lines are shown in Figure SI-2 of suppl. information. For each STM image is given the Fourier analysis where blue lines indicate the long-range ordered Pd NPs along the dot superstructure (4.12 $\mathrm{nm}$ periodicity), while green lines show the perylene adsorption phases.

Figure 2 shows a set of STM images of $0.9 \mathrm{~nm}$ large Pd NPs (Pd deposition of $0.05 \mathrm{ML}$ ) before and after perylene evaporation (0.4 and $1.2 \mathrm{ML}$ ) and their corresponding-Fourier analysis. Topography profiles along the dotted white lines are provided in supplementary information (Figure SI-2). For each STM image, a sketch of the surface organization is given. Pd nucleation and NP growth occur along the "dot" superstructure of alumina film with a $(\sqrt{67} \times \sqrt{67}) \mathrm{R} 12^{\circ}$ unit 
cell of $4.12 \mathrm{~nm}$ periodicity (Figure 2a and Figure SI-2). More details about the structural properties of these high-density narrow size distribution long-range ordered Pd NPs studied by STM and SFG can be found in ref. 21 where NP geometry and shape evolution with size and their impact on CO adsorption energy and reactivity are discussed. Evaporation of $0.4 \mathrm{ML}$ of perylene on these NPs, leads to the formation of an ordered hybrid assembly where perylene binds to the network adsorption sites in between the array of NPs with a $c(\sqrt{67} \times \sqrt{67}) \mathrm{R} 12^{\circ}\left(\mathrm{P}_{4}\right)$ unit cell (Figure $2 \mathrm{~b}$ and Figure SI-2a). The diameter of perylene is found to be $1 \mathrm{~nm}$ and its height is $1 \AA$ (Figure SI2b). STM images show no evidence of the binding of molecules on NPs. For larger perylene amount $(1.2 \mathrm{ML})$, the organization of molecules is quite different leading to more complex structures (Figure 2c). Several domains have been evidenced: (i) small (up to $3 \mathrm{~nm}$ large) ordered domains of perylene having a $\mathrm{P}_{2}$ phase, (ii) disordered regions and (iii) perylene adsorbing on NP perimeter. The diameter and height of individual molecules in ordered regions are similar to those of perylene on alumina without NPs. In disordered regions, intermolecular distances vary and can be smaller (down to $0.8 \mathrm{~nm}$ ), while heights are close to $2 \AA$ (Figure SI-2b). We also find that NP size has a crucial role for perylene ordering. The layer ordering after $1.2 \mathrm{ML}$ of perylene deposit on the alumina film with larger NPs of $1.4 \mathrm{~nm}$ diameter $(0.2 \mathrm{ML}$ of $\mathrm{Pd})$ is considerably reduced (Figure SI-3). Tip-surface convolution prevents to study the molecular organization between NPs, while local ordering mixing $\mathrm{P}_{1}$ and $\mathrm{P}_{2}$ adsorption phases can be observed on areas free of NPs.

DRS characterizations. $\triangle \mathrm{R} / \mathrm{R}$ spectra acquired by $\mathrm{DRS}$ during perylene deposition (up to $1.2 \mathrm{ML}$ ) on the bare alumina film and with 0.9 and $1.4 \mathrm{~nm}$ large NPs (0.05 and $0.2 \mathrm{ML}$ of Pd respectively) are presented in Figure 3a-c. In all cases, spectra are characterized by two absorption bands appearing at 1.61 and $2.80 \mathrm{eV}$ and growing in intensity with coverage. When NPs are present on 
the surface, a third band at $2.15 \mathrm{eV}$, proportional to perylene coverage and NP size, shows up from the early growth stage. Those features are superimposed on an increasing broad background that peaks in the UV, but only on bare alumina and with $0.9 \mathrm{~nm}$ NPs. The $2.80 \mathrm{eV}$ band has an energy very close to the known HOMO-LUMO transition of perylene. A close-up in the early stage of the growth shown in Figure SI-4, actually evidences the presence of two bands at $2.80 \mathrm{eV}$, in a good agreement with literature of perylene in liquid phase. ${ }^{48}$ Intensities of the 2.80 and $2.15 \mathrm{eV}$ bands as a function of the perylene coverage are displayed in Figure $4 a-b$ for the three experiments (0.0, 0.9 and $1.4 \mathrm{~nm}$ Pd NPs). They are obtained from the raw absorption corrected from the broadband background contribution.

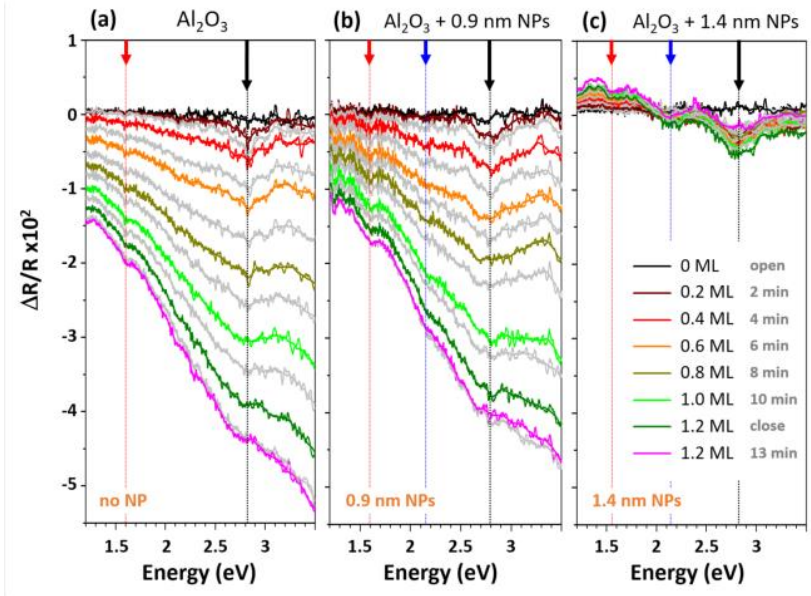

Figure 3. DRS spectra recorded during perylene deposition from 0 to 1.2 equivalent ML (a) on the bare alumina film and with NPs of (b) $0.9 \mathrm{~nm}$ and (c) $1.4 \mathrm{~nm}$ in size. Original and smoothed spectra are given. Three absorption bands at 1.61, 2.15 and $2.80 \mathrm{eV}$ are highlighted by red, blue and black arrows and dotted lines, respectively. Corresponding growth time with estimated coverage are given. Evaporator shutter is opened at $\mathrm{t}=0$ and closed after 12 $\min$, i.e $1.2 \mathrm{ML}$ of perylene according to STM. 
The absorption band at $2.80 \mathrm{eV}$ raises fast for perylene amount smaller than $0.1 \mathrm{ML}$ and then slows down until 0.2 ML and even saturates in the case without NPs up to $0.45-0.55 \mathrm{ML}$. On bare $\mathrm{Al}_{2} \mathrm{O}_{3}$ and with $0.9 \mathrm{~nm}$ Pd NPs, a transition occurs above $0.45-0.55 \mathrm{ML}$ where absorption starts to decrease continuously. For $1.4 \mathrm{~nm}$ NPs, the absorption continues to increase until the end of the growth. After closing the shutter, the absorption remains constant in the absence of NPs, while it decreases quickly in the presence of NPs before it stabilizes. The band intensity at $2.15 \mathrm{eV}$ is proportional to the amount of deposited Pd (Figure 4b). When the shutter is closed, it remains stable for small NPs while for the biggest NPs the band keeps on increasing at an even faster speed, even after the stabilization of the $2.80 \mathrm{eV}$ band. It can be due to a layer reorganization by surface diffusion or molecular reorientation rather than to desorption. It suggests that perylene molecules move from alumina to NPs at high coverage at a rate smaller than the adsorption rate. The integrated spectrum normalized by the photon energy and the deposited amount is also plotted (Figure 4c). ${ }^{49}$ In our nearly s-polarization configuration, this quantity is proportional to the integrated imaginary part of the dielectric function. ${ }^{50}$ Its evolution evidences three growth regimes: a slow regime (I) until $0.23 \mathrm{ML}$ on bare $\mathrm{Al}_{2} \mathrm{O}_{3}$ and $0.15 \mathrm{ML}$ with $0.9 \mathrm{~nm}$ large NPs, followed by a faster regime (II) until $0.53 \mathrm{ML}$ and $0.33 \mathrm{ML}$ with NPs and finally by a slower regime (III). The first two regimes are $33 \%$ faster in the presence of NPs, which might be explained by the 33\% occupancy of the network sites by NPs. The decrease of the $2.80 \mathrm{eV}$ absorption band after 0.45 $0.55 \mathrm{ML}$ is correlated to the start of growth regime III. 

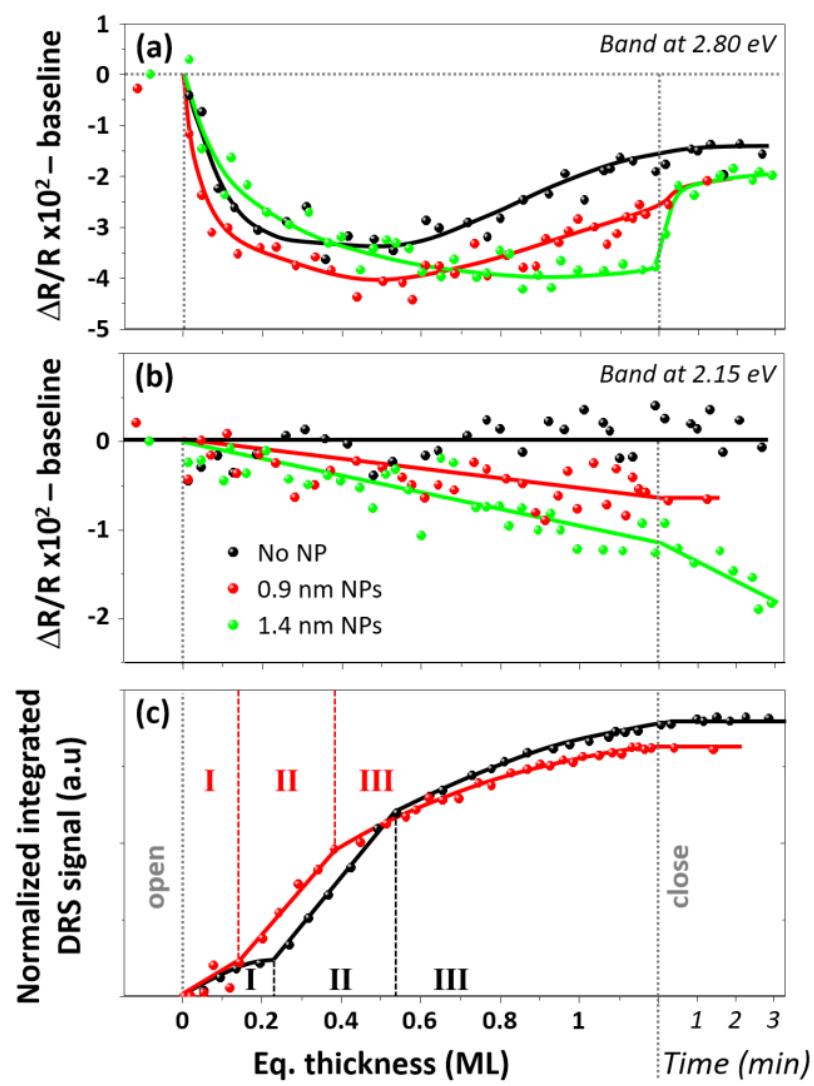

Figure 4. Coverage evolution of absorption bands at (a) $2.80 \mathrm{eV}$ and (b) $2.15 \mathrm{eV}$ during perylene growth on alumina without (black) and with NPs (red for $0.9 \mathrm{~nm}$ and green for $1.4 \mathrm{~nm} \mathrm{NPs}$ ) and (c) the normalized integrated DRS signal. Three regimes are highlighted. Perylene evaporator shutter is opened at $\mathrm{t}=0$ and closed after 12 min, i.e 1.2 equivalent ML of perylene.

Quantitative interpretation of DRS spectrum changes during the growth of organic layers requires the support of a complementary technique ${ }^{51}$ or theoretical calculations describing the change of the dielectric function with thickness. ${ }^{50,52}$ We have performed local spectroscopy measurements under the STM tip (STS) on a single molecule and a single nanoparticle in the case of 1.2 ML of perylene deposited on $0.9 \mathrm{~nm}$ Pd NPs (Figure 5a). The first derivative of the I(V) curves gives access to the local conductance which is proportional to the density of states. The similarity of the spectra recorded on top of a perylene molecule and on a NP is striking, considering that spectra are flat between -2 and $2 \mathrm{~V}$ on Pd NPs on alumina and on bare alumina. ${ }^{38}$ Therefore all 
features can be attributed to perylene, which is present at the perimeter NPs for $1.2 \mathrm{ML}$ of perylene, according to STM. Possible optical transitions at 1.61, 2.15 and $2.80 \mathrm{eV}$ are shown. The optical transition at $2.80 \mathrm{eV}$ is clearly present on perylene laying on alumina and on NPs. The band at $2.15 \mathrm{eV}$ is only observed in the presence of NPs by DRS, but STS measurements evidence that this band is present when perylene is laying on alumina and not on the NPs, suggesting that the electronic structure of perylene is different on alumina and in the vicinity of NPs. From the STS spectrum done on a perylene molecule, it is possible to simulate an UV/Vis absorption spectrum for comparison with DRS spectra. The calculation consists in integrating the product of pairs of conductivity $\sigma(V)=d l / d V$ having the same energy difference $\Delta E$. No assumption is done on selection rules and on transition moments. Only nonphysical optical transitions where the initial state $E_{i}$ is above Fermi level $\left(E_{F}\right)$ and the final state $E_{i}+\Delta E$ is below $E_{F}$ were excluded leading to the ]- $\Delta E ; 0\left[\right.$ possible interval for $E_{i}$. The simulated spectrum is given by Equation 1:

$$
S(\Delta E)=\int_{-\Delta E}^{0} \sigma\left(E_{i}\right) \times \sigma\left(E_{i}+\Delta E\right) d E_{i} \quad \text { Eq. } 1
$$

Because STS data are missing from 1.5 to $3 \mathrm{~V}$ and from -3 to $-1.5 \mathrm{~V}$, the STS spectrum has been linearly extrapolated to avoid underestimation of the optical response in the UV side $(3 \mathrm{eV})$. The final result is compared to three DRS spectra in Figure 5b corresponding to $0.4,0.6$ and $1.2 \mathrm{ML}$ of perylene, using only a scaling factor. This simple calculation is able to reproduce the UV broadband contribution and the main bands in DRS spectra. Nevertheless, small differences can be noticed. At low coverage, the transition dipole moment of the HOMO-LUMO transition at 2.80 eV seems underestimated by the calculation while at higher coverage, the situation is reversed. 

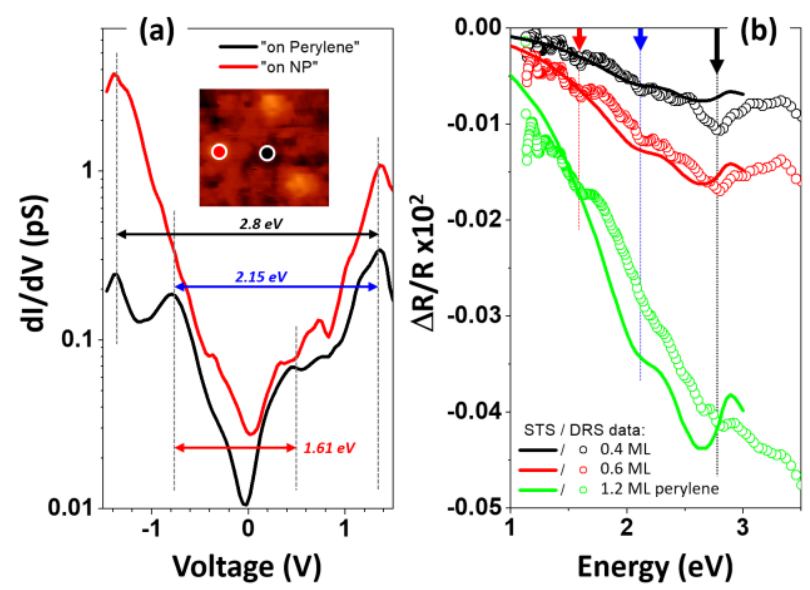

Figure 5. (a) STS measurements (averaged over 3 cycles and 5 positions) on $0.9 \mathrm{~nm}$ NPs (red line) and on perylene (1.2 ML, black line) as indicated in inset. Possible optical transitions found in DRS at 1.61, 2.17 and $2.80 \mathrm{eV}$ are highlighted. (b) Integrated STS spectrum done on perylene as a function of energy compared to DRS spectra of Figure 3, for 0.4, 0.6 and 1.2 $\mathrm{ML}$ perylene deposits. A scaling factor has been applied to compare simulations to DRS spectra.

SFG characterizations. Figure 6 shows SFG spectra of in-plane aromatic $\mathrm{C}-\mathrm{H}$ vibrations of perylene for 0.4 and $1.2 \mathrm{ML}$ deposits on bare alumina film and with 0.9 and $1.4 \mathrm{~nm}$ Pd NPs. The vibrational response from perylene is mixed with a non-resonant electronic signal arising from the surface that is often observed by SFG on metallic surfaces and has the Gaussian shape of the IR laser.

(i) For small amounts of perylene on alumina, $\mathrm{C}-\mathrm{H}$ vibration was detected at $v_{\mathrm{c}-\mathrm{H}}=3055 \mathrm{~cm}^{-1}$ frequency with a very small intensity $\left(\mathrm{I}_{\mathrm{C}-\mathrm{H}}\right)$ and a bandwidth $\Gamma_{\mathrm{C}-\mathrm{H}}=16.6 \mathrm{~cm}^{-1}$. The low intensity suggests that molecules are almost flat-lying, while the $14 \mathrm{~cm}^{-1}$ blue shift compared to the frequency of perylene on metal ${ }^{33}$ indicates an important difference in the nature of moleculesurface bonding, as expected on an insulator. In the presence of the smaller NPs, I $\mathrm{I}_{-\mathrm{H}}$ increases by a factor 6 with a larger $\Gamma_{\mathrm{C}-\mathrm{H}}=28 \mathrm{~cm}^{-1}$ and a $v_{\mathrm{C}-\mathrm{H}} 1 \mathrm{~cm}^{-1}$ blue-shifted (Figure $6 \mathrm{a}$ and $6 \mathrm{c}$ ). This intensity increase while coverage is smaller $(2 / 3)$ corresponds to a SFG sensitivity increase of $\approx 20$, which is typical of the presence of NPs, presumably due to field enhancement. ${ }^{21,53}$ 
(ii) For 1.2 ML perylene deposit on alumina, I $\mathrm{C}-\mathrm{H}$ raises $(\mathrm{x} 8)$ in proportion of the square of the coverage increase $(x 9)$, suggesting that molecules remain flat on the surface, the frequency changes significantly, by red-shifting to $3050.5 \mathrm{~cm}^{-1}$. With $0.9 \mathrm{~nm} \mathrm{NPs}, \mathrm{I}_{\mathrm{C}-\mathrm{H}}$ is stronger (x2.5) while coverage is presumably smaller according to STM (NPs occupy a significant fraction of the surface). This fits with the idea that molecules tilt and have a $\pi$-stacking type of intermolecular interaction: the intensity increase is due to an orientation effect (transition moment more vertical). The similar $v_{\mathrm{c}-\mathrm{H}}$ at $3050 \mathrm{~cm}^{-1}$ indicates that the major contribution to the red-shift is $\pi-$ stacking interactions (Figure $6 \mathrm{~b}$ and $6 \mathrm{c}$ ). With the larger $1.4 \mathrm{~nm} \mathrm{NPs,} \mathrm{v}_{\mathrm{C}-\mathrm{H}}$ is again strongly modified by shifting to $3058 \mathrm{~cm}^{-1}$ and the intensity increases much higher as we could expect with the considered coverage increase. It suggests a strong perturbation of perylene induced by the adsorption on NPs.
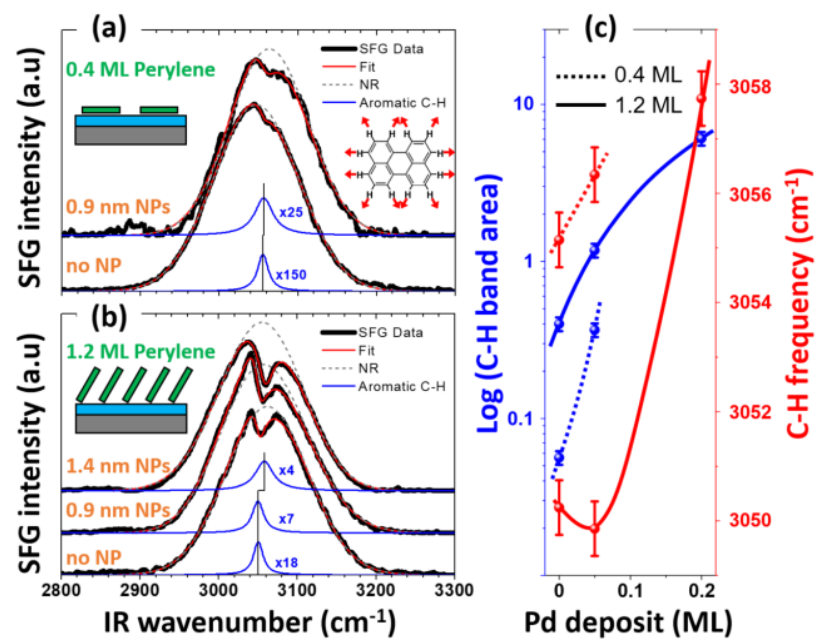

Figure 6. SFG spectra (black) of the in-plane aromatic $\mathrm{C}-\mathrm{H}$ vibration for (a) 0.4 and (b) 1.2 ML of perylene deposited on alumina thin film without and with Pd NPs (0.9 and $1.4 \mathrm{~nm}$ ). In addition are given the spectral fits (red) and the deconvoluted non-resonant signals (grey dotted line) and $\mathrm{C}-\mathrm{H}$ band (blue). (c) $\mathrm{C}-\mathrm{H}$ band intensity in logarithmic scale and frequency shift for 0.4 and 1.2 ML perylene deposit as a function of Pd deposited amount in equivalent ML. 
Finally thermal stability of the perylene layer as a function of NP size has been investigated by SFG. Results presented in Figure SI- 5 show that perylene starts to desorb above $100^{\circ} \mathrm{C}$ and the surface is free of perylene at $250^{\circ} \mathrm{C}$. It indicates that molecular stability relies mostly on aluminamolecule interactions, as expected considering that molecules are terminated by inert $\mathrm{C}-\mathrm{H}$ bonds. However, on the biggest NPs, a slightly higher temperature is required to completely desorb perylene, highlighting their stronger binding energy on NPs.

\section{- DISCUSSION}

Table 1 summarizes our observations and conclusions concerning the properties of the perylene layer as a function of perylene dose and NP presence and size. On bare alumina, a very well ordered organization of perylene is found.

Table 1. Properties of the perylene layer depending on NP size and perylene dose.

\begin{tabular}{|c|c|c|}
\hline & $0.4 \mathrm{ML}$ of perylene & 1.2 ML of perylene \\
\hline On alumina & $\begin{array}{l}1 \text { molecule per "network" unit cell } \\
\text { Ordered, flat lying }\end{array}$ & $\begin{array}{c}3 \text { molecules per "network" unit cell } \\
\text { Ordered, flat lying and tilted }\end{array}$ \\
\hline With $0.9 \mathrm{~nm}$ NPs & $\begin{array}{c}\text { Adsorption on alumina } \\
\text { 2/3 molecule per "network" unit cell } \\
\text { Ordered, flat lying } \\
\text { Enhanced sensitivity of SFG }\end{array}$ & $\begin{array}{c}\text { Adsorption mainly on alumina } \\
\text { Locally ordered, flat lying and tilted } \\
\text { Enhanced sensitivity of SFG }\end{array}$ \\
\hline With $1.4 \mathrm{~nm}$ NPs & $\begin{array}{l}\text { Adsorption on alumina and NPs } \\
\text { Disordered }\end{array}$ & $\begin{array}{c}\text { Adsorption on alumina and NPS } \\
\text { Disordered, tilted and coupled to NPS } \\
\text { Enhanced sensitivity of SFG }\end{array}$ \\
\hline
\end{tabular}

For deposits lower than 0.4 ML adsorption occurs on the "network" superstructure of the alumina film (period $2.38 \mathrm{~nm}$ ) (Figure 1c). Molecules are apparently lying flat on the surface. The weak 
SFG C-H intensity supports this interpretation that also matches with NEXAFS results. ${ }^{37}$ At coverages below $0.2 \mathrm{ML}$, two distinct optical transitions at $2.82 \mathrm{eV}$ and $3.03 \mathrm{eV}$ are visible in the DRS spectrum (Figure SI-4). They correspond exactly to the reported absorption bands of perylene in solvent ${ }^{48}$ and isolated (1/1000) in Ar cryogenic matrix at $20 \mathrm{~K},{ }^{54}$ suggesting that the interactions between alumina ions and perylene $\pi$-electrons are essentially electrostatic and do not shift the perylene HOMO-LUMO transition. However, this is not strictly true since the absorption band broadens during regime II of the growth kinetics. When all network sites are filled, the coverage can only increase by a layer compression which is obtained by tilting the molecules, giving rise to adsorption regime III (Figure 4c) where the intensity increases more slowly. Keeping in mind that the associated dipole of the HOMO-LUMO transition is collinear to the in-plane $\mathrm{C}_{2 \mathrm{v}}$-axis of the molecule, the observed decrease/increase of intensity of 2.80/2.15 eV bands are a signature of the upward tilting of the molecule since, in the present geometry, the electric field is nearly insurface-plane. In DRS, perylene tilt-up manifests itself from $0.55 \mathrm{ML}$. The reduced sensitivity of DRS at highest perylene deposits explains the discrepancy between DRS and optical spectra simulated from STS. By contrast, the coverage increase alone explains the observed SFG intensity increase, suggesting that the perylene hyperpolarizability is reduced by intermolecular $\pi$ stacking when molecules tilt up. The significant decrease of the $\mathrm{C}-\mathrm{H}$ frequency at this coverage confirms that the different coupling of the molecule with its environment modifies the $\mathrm{C}-\mathrm{H}$ band. By STM an increase of the layer thickness from 1 to $\approx 2.5 \AA$ is observed, supporting the idea that molecules tilt up by $\approx 12^{\circ}$ (assuming the tilting axis is the long molecular axis). However, the height of molecules as estimated by STM is not consistent with other data of the literature. Indeed, the thickness of a single layer of perylene with a $10^{\circ}$ tilt angle, measured by NEXAFS is $4 \AA{ }^{37}$ that is 
four times larger than measured by STM here. It suggests that perylene on alumina has a lower conductivity than the alumina layer. As a consequence of current regulation, tip comes closer to the surface above perylene, leading to a lower apparent molecular height of $1 \AA$. If we apply this factor 4 to correct the height of tilted molecules, we obtain a $10 \AA$ height, corresponding to a tilt of $70^{\circ}$ in agreement with the $67^{\circ}$ found by NEXAFS. Our results do not indicate the formation of multilayers.

The most important result of this study is the possibility to obtain an ordered hybrid layer of organic molecules and NPs. Molecules adsorb first on the alumina layer on network sites of 2.38 $\mathrm{nm}$ period as on bare alumina by inserting between NPs. They do not adsorb on the "dot" superstructure (period $4.12 \mathrm{~nm}$ ) where NPs stand and a 2:1 molecule:NP relative ratio can be reached at saturation of all available network sites. There is no hints that molecules stick to NPs at this stage. Adsorption of molecules beyond saturation coverage of this 2:1 structure produces a disordered surface, where molecules may tilt and occupy different types of sites on both alumina and NPs. This steric hindering is not a surprise because, at this coverage, there is not enough space between NPs to achieve an ordered layer as on alumina. For small NPs and low molecule coverage, SFG and DRS fingerprints are very similar to the bare alumina, indicating that molecules first lie flat on the surface and then tilt up when coverage exceeds that of the ordered structure. This ordering is not obtained if the NP size is increased to $1.4 \mathrm{~nm}$. In this case, DRS and SFG spectra show a striking difference compared to alumina and small NPs/alumina, namely the disappearance of the broadband and intense feature that peaks in the UV, showing that it is indeed related to alumina modified by perylene. SFG indicates a stronger frequency shift with respect to smaller NPs, which may be ascribed to the preferential bonding of perylene to NPs. 
This NP size limit does not seem to be related to the reduction of the space available for the molecules as NPs grow, since the distance between NPs of width $1.4 \mathrm{~nm}$ is $2.72 \mathrm{~nm}$, to be compared to the size of a perylene molecule of $0.9 \mathrm{~nm}$. The explanation might lie in the preference of molecules to stick on $1.4 \mathrm{~nm}$ NPs, then preventing ordered adsorption on alumina. By contrast, NPs of size $0.9 \mathrm{~nm}$ seem too small (7 atoms top-facet) for molecules to stick on them. ${ }^{21}$ The limit for perylene adsorption seems to be $\approx 14$ atoms (top facet of $1.4 \mathrm{~nm} \mathrm{NPs}$ ), corresponding to a terrace size of $\approx 1.1 \mathrm{~nm}$, which is comparable to the size of a perylene molecule. Alternatively a less favorable electronic structure of small NPs may favor a stronger adsorption of perylene on free alumina in between. Indeed, it was shown that Pd nanoparticles in this size range can change from a non-metallic to a metallic electronic structure, strongly affecting CO adsorption. ${ }^{20,21}$ This behavior could be a drawback to grow hybrid layers with "large" NPs. A strategy to prevent adsorption on NPs might be required, for example by a prior adsorption of molecules like CO that will occupy the adsorption sites of organic molecules.

\section{- CONCLUSION}

Through a multi-scale and multi-technique approach during and after the growth, we have demonstrated that a stable and ordered hybrid assembly containing Pd nanoparticles and perylene molecules can be formed on ultrathin $\mathrm{Al}_{2} \mathrm{O}_{3}$ film on $\mathrm{Ni}_{3} \mathrm{Al}(111)$. The combination of microscopy, local spectroscopy and macroscopic optical (UV/Vis and IR) spectroscopies allowed us determining organization, adsorption phases and molecular orientations in the hybrid layer as well as the relationship between electronic and optical properties. At the appropriate dose and 
NP size, molecules adsorb within the NP array, presumably as a result of a stronger moleculealumina coupling compared to metal-NP. At high coverage, molecules tilt up and adsorb also on Pd NPs. This model system demonstrates the feasibility to produce nanoscale, hybrid ordered assemblies and opens avenues to build systems with stronger bonding between NPs and molecules, e.g. by bridging them by thiol terminated linkers.

\section{- ASSOCIATED CONTENT}

S Supporting Information

(i) Fourier analysis and topography profiles of STM images.

(ii) STM images of larger Pd NPs and perylene molecules.

(iii) DRS spectra: Band intensities and small deposits.

(iv) Thermal stability of the perylene layer by SFG.

\section{- AUTHOR INFORMATION}

\section{Corresponding author}

*(A.O.) E-mail: aimeric.ouvrard@u-psud.fr

ORCID

Natalia Alyabyeva: 0000-0001-5999-5821

Aimeric Ouvrard: 0000-0003-3652-1222

Rémi Lazzari: 0000-0003-2354-1953

Bernard Bourguignon: 0000-0002-4171-6828 


\section{Present Address}

§N.A.: CNRS, Sorbonne Université, Institut des NanoSciences de Paris, UMR 7588, 4 Place Jussieu, F-75005 Paris, France.

\section{Notes}

The authors declare no competing financial interest.

\section{- ACKNOWLEDGMENTS}

We thank the "Agence Nationale pour la Recherche" for funding this work (LEMON project ANR-15-CE09-0007) and the Surfaces, Interfaces: Réactivité et Nanostructuration team (ISMO) for the loan of the molecular evaporation cell and helpful scientific discussions.

\section{- REFERENCES}

(1) Chen, Y-S.; Hong, M.-Y.; Huang G. S. A Protein Transistor Made of an Antibody Molecule and Two Gold Nanoparticles. Nat. Nanotech. 2012, 7, 197- 203.

(2) Aviram, A.; Ratner, M. A. Molecular Rectifiers. Chem. Phys. Lett. 1974, 29, 277-283.

(3) Editorial. Does Molecular Electronics Compute? Nat. Nanotech. 2013, 8, 377.

(4) Tans, S. J.; Verschueren, A. R. M.; Dekker, C. Room-Temperature Transistor Based on a Single Carbon Nanotube. Nature 1998, 393, 49-52.

(5) Tsutsui, M.; Taniguchi, M. Single Molecule Electronics and Devices. Sensors 2012, 12, 72597298.

(6) Aradhya, S. V.; Venkataraman, L. Single-Molecule Junctions Beyond Electronic Transport. Nat. Nanotech. 2013, 8, 399-410. 
(7) Perrin, M. L.; Frisenda, R.; Koole, M.; Seldenthuis, J. S.; Celis Gil, J. A.; Valkenier, H.; Hummelen, J. C.; Renaud, N.; Grozema, F. C.; Thijssen, J. M.; et al. Large Negative Differential Conductance in Single-Molecule Break Junctions. Nat. Nanotech. 2014, 9, 830-834.

(8) Schwarz, F.; Kastlunger, G.; Lissel, F.; Egler-Lucas, C.; Semenov, S. N.; Venkatesan, K., Berke, H.; Stadler, R.; Lörtscher, E. Field-Induced Conductance Switching by Charge-State Alternation in Organometallic Single-Molecule Junctions. Nat. Nanotech. 2015, 11, 170-177.

(9) Kitagawa, K.; Morita, T.; Kimura, S. Electron Transport Properties of Helical Peptide Dithiol at a Molecular Level: Scanning Tunneling Microscope Study. Thin Solid Films 2006, 509, 18-26.

(10) Na, J.-S.; Ayres, J.; Chandra, K. L.; Gorman, C. B.; Parsons, G. N. Real-Time Conductivity Analysis Through Single-Molecule Electrical Junctions. Nanotech. 2007, 18, 424001.

(11) Steurer, W.; Fatayer, S.; Gross, L.; Meyer, G. Probe-Based Measurement of Lateral SingleElectron Transfer Between Individual Molecules. Nat. Comm. 2015, 6, 8353.

(12) Steurer, W.; Repp, J.; Gross, L.; Scivetti, I.; Persson, M.; Meyer, G. Manipulation of the Charge State of Single Au Atoms on Insulating Multilayer Films. Phys. Rev. Lett. 2015, 114, 036801.

(13) Becker, C.; Rosenhahn, A.; Wiltner, A.; von Bergmann, K.; Schneider, J; Pervan, P.; Milun, M.; Kralj, M.; Wandelt, $\mathrm{K} . \mathrm{Al}_{2} \mathrm{O}_{3}$-Films on $\mathrm{Ni}_{3} \mathrm{Al}(111)$ : a Template for Nanostructured Cluster Growth. New J. of Phys. 2002, 4, 75.1-75.15.

(14) Buchsbaum, A.; De Santis, M.; Tolentino, H. C. N.; Schmid, M.; Varga, P. Highly Ordered Pd, Fe, and Co Clusters on Alumina on $\mathrm{Ni}_{3} \mathrm{Al}(111)$. Phys. Rev. B 2010, 81, 115420.

(15) Marsault, M.; Sitja, G.; Henry, C. R. Regular Arrays of Pd and PdAu Clusters on Ultrathin Alumina Films For Reactivity Studies. Phys. Chem. Chem. Phys. 2014, 16, 26458-26466.

(16) Gavioli, L.; Cavaliere, E.; Agnoli, S.; Barcaro, G.; Fortunelli, A.; Granozzi, G. Template-Assisted Assembly of Transition Metal Nanoparticles on Oxide Ultrathin Films. Prog. in Surf. Sci. 2011, $86,59-81$. 
(17) Torelli, P.; Soares, E.A.; Renaud, G.; Gragnaniello, L.; Valeri, S.; Guo, X.; Luches, P. Self-Organized Growth of $\{\mathrm{Ni}\}$ Nanoparticles on a Cobalt-Oxide Thin Film Induced by a Buried Misfit Dislocation Network. Phys. Rev. B 2008, 77, 081409.

(18) N’Diaye, A. T.; Gerber, T.; Busse, C.; Myslivecek, J.; Coraux, J.; Michely, T. A Versatile Fabrication Method for Cluster Superlattices. New J. Phys. 2009, 11, 103045.

(19) Gerber, T.; Knudsen, J.; Feibelman, P. J.; Granas, E.; Stratmann, P.; Schulte, K.; Andersen, J. N.; Michely, T. CO-Induced Smoluchowski Ripening of Pt Cluster Arrays on the Graphene/Ir(111) Moiré. ACS Nano 2013, 7, 2020-2031.

(20) Sitja, G.; Le Moal, S.; Marsault, M.; Hamm, G.; Leroy, F.; Henry, C. R. Transition from Molecule to Solid State: Reactivity of Supported Metal Clusters. Nano Lett. 2013, 13, 1977-1982.

(21) Alyabyeva, N.; Ouvrard, A.; Zakaria, A.-M.; Bourguignon, B. Probing Nanoparticle Geometry down to Subnanometer Size: The Benefits of Vibrational Spectroscopy. J. Phys. Chem. Lett. 2019, 10, 624-629.

(22) Vlaic, S.; Gragnaniello, L.; Rusponi, S.; Cavallin, A.; Donati, F.; Dubout, Q.; Piamonteze, C.; Dreiser, J.; Nolting, F.; Brune, H. Interlayer Exchange Coupling in Ordered Fe Nanocluster Arrays Grown on $\mathrm{Al}_{2} \mathrm{O}_{3} / \mathrm{Ni}_{3} \mathrm{Al}(111)$. Phys. Rev. B 2014, 89, 245402.

(23) Leroy, F.; Renaud, G.; Letoublon, A.; Lazzari, R.; Mottet, C.; Goniakowski, J. Self-Organized Growth of Nanoparticles on a Surface Patterned by a Buried Dislocation Network, Phys. Rev. Lett., 2005, 95,185501.

(24) Brune, H. Microscopic View of Epitaxial Metal Growth: Nucleation and Aggregation. Surf. Sci. Rep. 1998, 31, 125.

(25) Draper, E. R.; Walsh, J. J.; McDonald, T. O.; Zwijnenburg, M. A.; Cameron, P. J.; Cowan, A. J.; Adams, D. J. Air-Stable Photoconductive Films Formed From Perylene Bisimide Gelators. J. Mater. Chem. C 2014, 2, 5570-5575. 
(26) Saikia, D.; Sarma, R. Organic Light-Emitting Diodes with a Perylene Interlayer Between the Electrode-Organic Interface. J. of Electr. Mat. 2018, 47, 737-743.

(27) Bobrov, K.; Kalashnyk, N.; Guillemot, L. True Perylene Epitaxy on Ag(110) Driven By Site Recognition Effect. J. Chem. Phys. 2015, 142, 101929.

(28) Tautz, F.S. Structure and Bonding of Large Aromatic Molecules on Noble Metal Surfaces: The Example of PTCDA. Prog. in Surf. Sci. 2007, 82, 479-520.

(29) Eremtchenko, M.; Schaefer, J. A.; Tautz, F.S. Understanding and Tuning the Epitaxy of Large Aromatic Adsorbates by Molecular Design. Nature 2003, 425, 602-605.

(30) Bobrov, K.; Kalashnyk, N.; Guillemot, L. Thermodynamic Balance of Perylene Self-Assembly on Ag(110). J. Chem. Phys. 2016, 145, 154705.

(31) Momeni, A.; Staicu Casagrande, E. M.; Dechaux, A.; Khemliche, H. Ultrafast Crystallization Dynamics at an Organic-Inorganic Interface Revealed in Real Time by Grazing Incidence Fast Atom Diffraction. J. Phys. Chem. Lett. 2018, 9, 908-91.

(32) Eremtchenko, M.; Bauer, D.; Schaefer, J. A.; Tautz, F. S. Structure, Bonding, and Growth at a Metal-Organic Interface in the Weak Chemisorption Regime: Perylene - Ag(111). J. Mater. Res. 2004, 19, 2028.

(33) Kalashnyk, N.; Amiaud, L.; Dablemont, C.; Lafosse, A.; Bobrov, K.; Guillemot, L. Strain Relaxation and Epitaxial Relationship of Perylene Overlayer on Ag(110). J. Chem. Phys. 2018, 148, 214702.

(34) Ong, K. K.; Jensen, J. O.; Hameka, H. F. Theoretical Studies of the Infrared and Raman Spectra of Perylene. J. Mol. Struct.: THEOCHEM 1999, 459, 131-144.

(35) Kilian, L.; Hauschild, A.; Temirov, R.; Soubatch, S.; Schöll, A.; Bendounan, A.; Reinert, F.; Lee, T.L.; Tautz, F. S.; Sokolowski, M.; et al. Role of Intermolecular Interactions on the Electronic and Geometric Structure of a Large $\pi$-Conjugated Molecule Adsorbed on a Metal Surface. Phys. Rev. Lett. 2008, 100, 136103. 
(36) Moors, M.; Krupski, A.; Degen, S.; Kralj, M.; Becker, C.; Wandelt, K. Scanning Tunneling Microscopy and Spectroscopy Investigations of Copper Phthalocyanine Adsorbed on $\mathrm{Al}_{2} \mathrm{O}_{3} / \mathrm{Ni}_{3} \mathrm{Al}(111)$. App. Surf. Sci. 2008, 254, 4251-4257.

(37) Casu, M. B.; Schöll, A.; Rudolf Bauchspiess, K.; Hübner, D.; Schmidt, T.; Heske, C.; Umbach, E. Nucleation in Organic Thin Film Growth: Perylene on $\mathrm{Al}_{2} \mathrm{O}_{3} / \mathrm{Ni}_{3} \mathrm{Al}(111)$. J. Phys. Chem. C 2009, $113,10990-10996$.

(38) Alyabyeva, N.; Ouvrard, A.; Zakaria, A. M.; Charra, F.; Bourguignon, B. Transition from Disordered to Long-Range Ordered Nanoparticles on $\mathrm{Al}_{2} \mathrm{O}_{3} / \mathrm{Ni}_{3} \mathrm{Al}(111)$. Appl. Surf. Sci. 2018, $444,423-429$.

(39) Schmid, M.; Kresse, G.; Buchsbaum, A.; Napetschnig, E.; Gritschneder, S.; Reichling, M.; Varga, P. Nanotemplate with Holes: Ultrathin Alumina on $\mathrm{Ni}_{3} \mathrm{Al}(111)$. Phys. Rev. Lett. 2007, 99, 196104.

(40) Marsault, M.; Hamm, G.; Wörz, A.; Sitja, G. B. C.; Henry, C. Preparation of Regular Arrays of Bimetallic Clusters with Independent Control of Size and Chemical Composition. Faraday Discuss. 2008, 138, 407-420.

(41) Lazzari, R.; Jupille, J. Growth Kinetics and Size-Dependent Wetting of $\mathrm{Ag} / \alpha-\mathrm{Al}_{2} \mathrm{O}_{3}(0001)$ Nanoparticles Studied via the Plasmonic Response. Nanotechnology 2012, 23, 135707.

(42) Konoplev, B.G.; Ageev, O.A.; Smirnov, V.A.; Kolomiitsev, A.S.; Serbu, N.I. Probe Modification for Scanning Probe Microscopy by the Focused Ion Beam Method. Rus. Microelect. 2012, 41, 4150.

(43) Horcas, I.; Fernández, R.; Gómez-Rodríguez, J. M.; Colchero, J.; Gómez-Herrero, J.; Baro, A.M. WSXM: A Software for Scanning Probe Microscopy and a Tool for Nanotechnology. Rev. Sci. Instrum. 2007, 78, 013705. 
(44) Ouvrard, A.; Wang, J.; Ghalgaoui, A.; Nave, S.; Carrez, S.; Zheng, W.; Dubost, H.; Bourguignon, B. CO Adsorption on Pd(100) Revisited by Sum Frequency Generation: Evidence for Two Adsorption Sites in the Compression Stage. J. Phys. Chem. C 2014, 118, 19688-19700.

(45) Wang, J.; Dubost, H.; Ghalgaoui, A.; Zheng, W.; Carrez, S.; Ouvrard, A.; Bourguignon, B. Effect of Visible Pulse Shaping on the Accuracy of Relative Intensity Measurements in BBSFG Vibrational Spectroscopy. Surf. Sci. 2014, 626, 26-39.

(46) Hamm, G.; Barth, C.; Becker, C.; Wandelt, K.; Henry, C. R. Surface Structure of an Ultrathin Alumina Film on $\mathrm{Ni}_{3} \mathrm{Al}(111)$ : A Dynamic Scanning Force Microscopy Study. Phys. Rev. Lett. 2006, $97,126106$.

(47) Degen, S.; Krupski, A.; Kralj, M.; Langner, A.; Becker, C.; Sokolowski, M.; Wandelt, K. Determination of the Coincidence Lattice of an Ultra-Thin $\mathrm{Al}_{2} \mathrm{O}_{3}$ Film on $\mathrm{Ni}_{3} \mathrm{Al}(111)$. Surf. Sci. 2005, 576, 57-64.

(48) Berlman, I. B. Handbook of Fluorescence Spectra of Aromatic Molecules. Academic Press, N.Y. 1971.

(49) Lazzari, R.; Jupille, J. Quantitative Analysis of Nanoparticle Growth Through Plasmonics. Nanotechnology 2011, 22, 445703.

(50) Lazzari, R.; Simonsen, I.; Jupille, J. Interfacial Susceptibilities in Nanoplasmonics via Inversion of Fresnel Coefficients. Plasmonics 2014, 9, 261-272.

(51) Ghanbari, E.; Wagner, T.; Zeppenfeld P. Layer-Resolved Evolution of Organic Thin Films Monitored by Photoelectron Emission Microscopy and Optical Reflectance Spectroscopy. J. Phys. Chem. C 2015, 119, 24174-24181.

(52) Lazzari, R.; Jupille, J.; Cavallotti, R.; Simonsen, I. Model-Free Unraveling of Supported Nanoparticles Plasmon Resonance Modes. J. Phys. Chem. C 2014, 118, 7032-7048. 
(53) Ouvrard, A.; Ghalgaoui, A.; Michel, C.; Barth, C.; Wang, J.; Carrez, S.; Zheng, W.; Bourguignon, B.; Henry, C. R. CO Chemisorption on Ultrathin MgO-Supported Palladium Nanoparticles. J. Phys. Chem. C 2017, 121, 5551-5564.

(54) Joblin, C.; Salama, F.; Allamandola, L. Absorption and Emission Spectroscopy of Perylene $\left(\mathrm{C}_{20} \mathrm{H}_{12}\right)$ Isolated in Ne, Ar, and $\mathrm{N}_{2}$ Matrices. J. Chem. Phys. 1999, 110, 7287-7297.

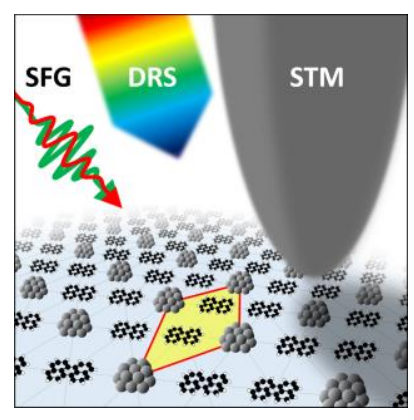

TOC graphic 